DOI: $10.30519 /$ ahtr.453268

Advances in Hospitality and Tourism Research (AHTR)

\title{
THE IMPACTS OF HOST PHOTOS ON CONSUMER PURCHASE PROBABILITY IN P2P SHORT-TERM RENTAL PLATFORM: MEDIATING EFFECT OF INITIAL TRUST
}

\author{
Hui WU ${ }^{1}$ \\ College of Business Administration, Hunan University, China \\ ORCID: 0000-0002-1189-6100 \\ Jing CHEN \\ College of Business Administration, Hunan University, China \\ ORCID: 0000-0001-6937-7912 \\ Muhittin CAVUSOGLU \\ College of Education, University of South Florida, USA \\ ORCID: 0000-0003-2272-1004 \\ Cihan COBANOGLU \\ College of Hospitality $\mathcal{E}$ Tourism Leadership, University of South Florida Sarasota- \\ Manatee, USA \\ ORCID: 0000-0001-9556-6223
}

\begin{abstract}
In recent years, the shared housing rental platform (hereafter, the short-term rental platform), designed to serve the Peer-2-Peer (P2P) market, has flourished and received extensive attention from the business community and academia. However, few studies have focused on the effect of hosts' personal information on consumer purchase behavior. This article selects the host's photo as an entry point because of its important position in the site interface and builds a conceptual framework among host photo, reputation, initial trust, and consumer purchase probability based on Face Processing Theory. Three-hundred valid, scenario-based questionnaires were used for hypotheses testing. Results show that photo-based social impression
\end{abstract}

\section{Article History}

Received 13 August 2018

Revised 7 January 2019

Revised 27 May 2019

Accepted 29 May 2019

\section{Keywords}

reputation

perceived social impression sharing economy face processing theory photo-based social impression

\footnotetext{
1 Address correspondence to Hui Wu, College of Business Administration, Hunan University,
} CHINA. E-mail: wuhuish@163.com 
perception and reputation both help consumers form initial trust, which ultimately affects consumer purchase probability ; photo-based perceived social impression has a greater impact on initial trust and purchase probability than does reputation. Results will provide some guidance for the marketing management of sharing platform organizations.

\section{INTRODUCTION}

With the development of network technology, the traditional economic model has undergone earth-shaking changes, contributing to the birth of the sharing economy. Established in 2008, Airbnb, a model of a shared housing rental platform within the sharing economy, has reached a market value of US \$31 billion (Smith, 2018). However, compared to foreign countries, the sharing economy in China developed slightly later. It firstly emerged in 2010 and has flourished in many fields. Examples include accommodation services (e.g. Ant Short Rent), taxi services (e.g. Didi), and bike services (e.g. Mobike). Using the shared housing rental platform as an example, the China Shared Accommodation Development Report (2018), released by the Sharing Economy Research Center of National Information Center, pointed out that China's online short-term rental business played an important role in the local accommodation market. The market transaction volume was 8.5 billion RMB yuan in 2016 and grew to 14.5 billion RMB yuan (2.28 billion US dollars) in 2017, with a high growth rate of $70.6 \%$, and is expected to reach 50 billion yuan in 2020 (National Information Center, 2018).

The shared housing rental platform (hereafter referred to as the tourism short-term rental platform), is a place where house owners provide their personal houses or just a single room for people to rent. The utility of the shared housing rental platform is similar to the third-party platform because it provides a separate space in which two kinds of users, consumers and suppliers, can benefit from peer-to-peer (P2P) transactions. The existing research focusing on tourism short-term rental sites can almost be divided into three aspects. The first mainly concentrates on the business model, problems in development, and how to solve these problems. The second is for understanding consumers' motivations to use the sharing platform, while the third often focuses on website platforms (such as website usability, usefulness and entertainment, system construction, etc.), room attributes (such as room prices, area, location, etc.), and other factors (such as online reviews and historical purchase 
quantity, etc.) that influence consumers' purchase attitudes and behaviors. However, when consumers browse short-term rental sites, such as Airbnb or similar platforms, e.g., Ant Short Rental, it is easy to observe an interesting phenomenon; next to photos of the living space, the website also requires hosts to upload their personal portrait photos. The questions to answer are: What impact do personal photos of the hosts have on the consumer's psychology and behavior? and What is the influence mechanism among them? So, doing will not only help explain the special phenomenon and uncover how the interface factors of short-term rental sites affect consumers' purchase intention in theoretical implications of the present research, but also provide important managerial and practical implications for managers of P2P rental platforms and hosts to facilitate online transactions.

Despite the importance of hosts' personal information, little empirical effort has been made to address the relationship between hosts' personal information and consumer purchase intention in the field of tourism P2P short-term rental. With respect to the literature search results, only a few articles came to our attention. Ert et al. (2016) showed that the more trustworthy and attractive the host's photos, the higher the consumers' intention to lease the accommodation directly. In a similar vein, Fagerstrøm et al. (2017) studied the impact of hosts' facial expressions in their photos upon the consumers' approach and avoidance tendency, and the results showed that hosts with positive facial expressions tend to evoke higher approach tendency and less avoidance tendency as opposed to negative facial expressions. Ma et al. (2017) found that the text-based self-descriptions and trustworthiness of Airbnb host profiles might influence consumer behavior. They argued that longer selfdescriptions and a mix of topics on Airbnb profile pages are perceived to be more trustworthy, with the ability to positively predict consumer choice for the host on Airbnb.

During the decision-making process, constrained by information asymmetry between hosts and buyers, consumers are always concerned about whether property and personal safety can be guaranteed and whether the host's information is credible (Ert et al., 2016). Thus, when choosing an accommodation, consumers may go through a timeconsuming process (Xie \& Mao, 2017). Consequently, customer trust has become a prerequisite for maintaining the steady development of the platform because the transaction can be deterred easily if consumers do not trust the host. In recent years, scholars have confirmed that the formation and development process of trust is dynamic, which can be 
divided into two phases: exploration (initial trust) and commitment (continuous trust) (Chang et al., 2014; McKnight et al., 2002). Initial trust is the essential basis for future continuous trust which will predict the trustor's further understanding of platform information and transaction decision making (Jarvenpaa et al., 2000). Therefore, it is necessary to understand the role of initial trust under the P2P short-term rental platform. The current research defines initial trust as a subjective trustful behavior, based on social judgments of the host's photos and reputation when the consumer is browsing the site interface. To reveal the intrinsic mechanism of how consumers' behavior is affected by hosts' photos and reputation (e.g. review point), we introduce the variable of initial trust into the conceptual framework.

Although prior studies have achieved a lot, several research gaps can be observed in the literature review. On the one hand, photo-based social impression research is not well understood. Specifically, the five fundamental dimensions underlying photo-based social judgement have been identified, i.e., trustworthiness (Yang, 2014), attractiveness (Ert et al., 2016), competence (Todorov et al., 2005), dominance, and confidence (White et al., 2017). However, past research focused much on trustworthiness and attractiveness (Ert et al., 2016; Ma et al., 2017). On the other hand, some factors closely associated with P2P tourism platforms, such as initial trust, have not received attention despite their crucial implications for the P2P sharing economy. Rare studies have explored antecedents and consequences of initial trust in the field. As Lewis and Weigert (1985) said, trust is deeply and closely related to the context. Therefore, this paper aims to find what factors will influence initial trust when a consumer is browsing the site interface.

In view of the existing research deficiencies, based on Face Processing Theory, this work applies the empirical method to examine the possible relationship among hosts' photos, hosts' reputation, initial trust and purchase probability. This paper uncovers the black box of how hosts' personal information influences consumer purchase probability. The paper attempts to reveal the effects of photo-based social impression perception and hosts' reputation on consumer purchase probability and its mechanism. Hence, it provides substantial evidence and practical marketing implications for P2P platforms and hosts. 


\section{LITERATURE REVIEW}

\section{Theoretical Basis}

Face Processing Theory argues that we can readily infer much information from faces, accordingly, gaining their inner and hidden essence and thoughts (Lu et al., 2010). Similarly, some scholars tried to use physiognomy for better understanding of the phenomenon (Todorov et al., 2015), stating that visual appearance is a window to the soul. They tried to explain the phenomenon from the view of evolution, for primitive humans wanted to recognize people who were willing to cooperate and share their resources. In our daily life, we inadvertently make trait inferences and social judgement based on strangers' facial appearance, which is called face processing. In general, people with a smile often give others a better impression, implying a character which is approachable and warm, while neutral facial expressions reflect a more rational and logical impression. Wang et al. (2016) noted that individuals with a broad smile were perceived as warmer but less competent than were individuals with a slight smile. Such judgement appears to predict individual decision making; for example, candidates who seem more attractive can easily be hired and get higher salaries (Aimei et al., 2009).

\section{Photo-Based Social Impression Perception}

While our accurate judgment of whether a person is worthy of trust in life requires long-term interaction and communication, we often make judgments of whether someone is trustworthy based on an occasional encounter in real life. Generally, the length of time it takes to form a social judgement through photographs is no more than 0.1 seconds (Olivola \& Todorov, 2010; Willis \& Todorov, 2010). Further, photo-based social impression perception will not change in a short time. Impression perception is basically automatic and uncontrolled and is robust and fast (Todorov et al., 2009). Its formation process mainly takes place through stable, implicit cognitive schemata processing. In this article, social impression perception is conceptualized as the extent of integral perception through hosts' photo exposure.

Numerous studies have proved the important role of face-based trait evaluation in interpersonal communication and trust (Bente et al., 2012; Olivola et al., 2014). For example, Stirrat and Perrett (2010) noted that after paralyzing the impact of familiarity and emotions variables, the 
likelihood of obtaining cooperation and reciprocity is higher for people with trustworthy faces, which directly influences social decision results such as purchasing behavior intentions. In the initial stage, due to the lack of relevant and available information between interaction partners, this effect is more significant, especially in a situation like computer-mediated communication. Moreover, a face-based social impression will show a continuous guiding effect on subsequent multiple judging and decisionmaking behaviors ( $\mathrm{Xu}$ et al., 2013).

Regarding the P2P short-term rental context, the purpose of hosts' photos is to display multi-dimensional signals through social cues. Specifically, when consumers browse the website and make eye contact with hosts' portrait photos in the unconscious situation, they occasionally and unconsciously will form the first impression to strange encounters, i.e., initial trust and decision making. The underlying effects of the photos are: 1) conveying visual signals relevant to the social impression perception and 2) expressing the hosts' willingness to cooperate by exposing their private information and disclosing their identities to consumers. Hence, the behavior of uploading private portrait symbolizes that the host is sincere and trustworthy, which holds a potential contribution to foster and prompt initial trust (Todorov et al., 2005). Ert et al. (2016) discovered the potential and positive relation of photo-based trustworthiness and attractiveness in Airbnb with the probability of successful accommodation booking through the experiment methods. In summary, it was hypothesized that photo-based perception has a positive effect on consumers' attitude and behavior intention, stated as Hypothesis 1 and Hypothesis 2:

H1: Photo-based social impression perception positively affects consumer initial trust.

H2: Photo-based social impression perception positively affects consumer purchase probability.

\section{Host Reputation}

With the development of network information technology and online transactions, online shopping has become a giant trading market. However, due to the difficulty in face-to-face contact with services and products, customers perceive high trade risks and uncertainty regarding the quality of products, as it cannot be verified. Reputation, an intangible 
indicator of product quality assessment, is a core element for decision making. It originates from consumers with purchasing and consuming experience, and it developed through consumers' feedback in the form of text reviews, star ratings, and other ways. In line with that, the essence of reputation is facilitating online trust and strengthening trading confidence (Wu et al., 2011).

Past empirical research on online reputation dates to the emergence of eBay. Scholars adopted both second-hand data and experimental evidence to confirm how reputation affects transaction behaviors (Hayne et al., 2015; Hui et al., 2016). Findings suggested that when a host's reputation was higher, consumers intended to pay more money for the auction. In addition, consumers' perceived risks and uncertainty were lower during the process of purchasing decision making. Similarly, Melnik and Alm (2005) also concluded that host's overall reputation positively influenced consumers' willingness to pay. In the domain of tourism, several previous studies have addressed the positive impact of reputation. Recently, Ert et al. (2016), regarding the booming development of Airbnb, found that hosts who have a high reputation attract consumers to generate a positive attitude and strong willingness to pay, in a sense. Research conducted by Bente et al. (2012), from the perspective of Signal Theory, differentiated the impacts of reputation scores and host photos. They found that photos from a host who has a positive reputation (signaling s/he is worthy of being trusted) and is trustworthy, are more likely to gain trust and high purchase rates.

Reputation, as an explicit propositional clue that cannot be ignored, has been shown to function as the antecedent to consumer trust and purchase probability. Thus, we take the host's reputation as a driving factor and independent variable. In sum, in the P2P platform, the following hypotheses are proposed:

H3: The host's reputation has a positive effect on initial trust.

H4: The host's reputation has a positive effect on consumer purchase probability.

\section{Mediation of Initial Trust}

Trust is a process-based outcome that changes dynamically over time and interactions (Ennew et al., 2011). Continuous trust is pulled directly from familiar parties who share credible information with each other and is 
often based on direct interaction (McKnight et al., 2002; Stouthuysen et al., 2018). It differs from the initial stage in which buyers desperately lack firsthand knowledge or prior experience, yet it is cultivated by frequent interaction and abundant communication between hosts and buyers. Doney and Cannon (1997) defined initial trust as subjective credibility, i.e. when trust parties first encounter each other in a temporary buying context, the trustor perceives the credibility and benevolence of a target of trust. Lee and Choi (2011) claimed that initial trust refers to the willingness to believe in others even in the absence of trustee information and interaction. When both parties are strangers, and in the risk of information asymmetry, they have to resort to contextual cues when making decisions. Some contend that consumers evaluate visual situational cues (i.e. host photo and reputation) in terms of first eye contact and overall perception of the unfamiliar host in the P2P short rental platform to gain initial trust (Fagerstrøm et al., 2017).

In the initial phase of online shopping, inspiring initial trust is important for consumers' buying decisions. Ridings et al. (2002) believed that initial trust can reduce complexity and perceived risk because it lacks face-to-face contact, and thus help predict the downstream effects of both giving and getting information behavior through a virtual community. Research by Jarvenpaa et al. (2000) showed that consumers recognized differences in hosts' reputation and would ultimately increase their willingness to patronize by reducing perceived risk. In conclusion, it was suggested that, after the formation of initial trust, consumers gradually generate confidence and expectation regarding the accommodation supplied by the hosts, and consequently enhance their online purchase probability. Hence, the following hypothesis is proposed:

H5a: Initial trust mediates the relationship between photo-based social impression perception and consumer purchase probability.

H5b: Initial trust mediates the relationship between host reputation and consumer purchase probability.

Based on the assumptions above, this paper proposes the conceptual framework and hypotheses below (see Figure 1). 


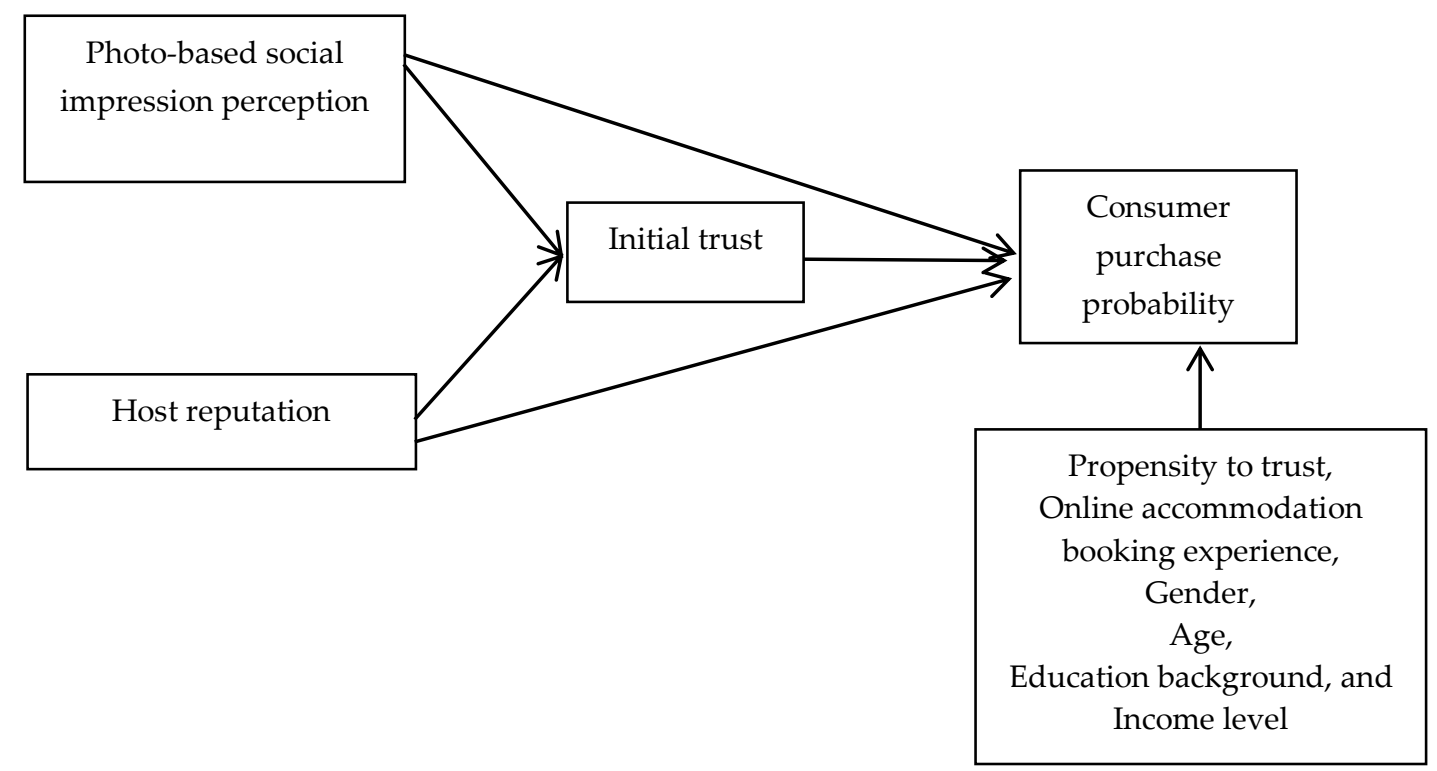

Figure 1. Conceptual framework

\section{RESEARCH DESIGN}

\section{Pretests}

To ensure the validity of experimental stimuli in formal situation questionnaires, two independent pretests were conducted.

Pretest 1 . Ten ambient male snapshots were selected from a famous short-term rental platform in China. The selection criteria were clear and legible, with the same pixel $(120 \times 120)$, no covering the face, e.g. eyeglasses, hair, hands, and no visible makeup, as well as assuring that all photos were frontal headshots. Twenty-two individuals (11 women and 11 men) were recruited online. The participants were asked to complete the online survey. Participants were informed that this study was designed to examine people's first impression. They were shown one of the selected photos and asked to judge the age, attractiveness, warmth, and competence perceptions of the target on a seven-point scale $(1=$ strongly disagree, 7 = strongly agree). The proportion of respondents were similar to previous studies (Bente et al., 2012). In the main study, based on the prior research and combined with the features of the short-term rental platform, we added the scores of two items' scale (competence and warmth) into one, taking the average rating value to symbolize the independent variable, social impression perception. In Pretest 1, in an 
attempt to control the potential effects of stimulus' age and attractiveness on choice, we finally selected two photos with similar ranking. Manipulation and confound checks suggested no differential between the two photos, respectively ratings of age $\left(\mathrm{M}_{\mathrm{P} 1}=1.91, \mathrm{M}_{\mathrm{P} 2}=2.00, p=0.58\right.$, representing the same-aged stimuli $)$ and attractiveness $\left(\mathrm{MP}_{\mathrm{P}}=4.55, \mathrm{MP}_{\mathrm{P}}=\right.$ $4.10, p=0.18$, representing the same attractive perception), thereby excluding their impacts on experimental outcomes.

Pretest 2. Pretest 2 was conducted to test the effectiveness of the reputation manipulation. Forty-four participants were recruited online and randomly assigned either the high or low reputation condition. To select the appropriate reputation scores for the main study, a second pretest was conducted, under the foundation of Joo (2015). All possible cases (1-5 stars) were shown to participants to ask for the trust rating on a seven-point Likert scale. Results show that $69.8 \%$ of the participants believe 4.5 stars or more is trustworthy, whereas $76.7 \%$ think 4.0 stars or less is not trustworthy. To better distinguish between high and low reputation, 3.0 stars and 5.0 stars were selected to manipulate reputation, which is consistent with prior research (Bente et al., 2012).

\section{Procedure}

To make this research as realistic as possible, participants were shown screenshots from the Mayi website (www.mayi.com), a popular short-term rental website in China, to improve their understanding. Adobe Photoshop software was used to prepare the survey stimuli. In the survey, all the information in screenshots was the same, except the host photo and reputation score. Firstly, participants were informed that this study examined people's attitude towards the short-term rental website. To allow participants to integrate into the questionnaire situation, they were guided to imagine that they were visiting an online short-term rental website to choose an accommodation for holidays. Then, they read one of four questionnaires (two host photos * two host reputation) and completed the survey immediately.

\section{Sample and Data Collection}

Undergraduate and graduate students (including MBA) were chosen as the target population for reasons which can be stated as: 1) China Shared Accommodation Development Report 2018 mentioned that most users of 
this rental site are millennials, young adults aged 20-40 years and generally highly educated (National Information Center, 2018); 2) The young adult group is the main force in online accommodation booking websites with abundant booking experience (Kucukusta et al., 2015); and 3) Student samples are justifiable, as they have few problems using new technology and are potential market consumers of these P2P platforms (Transparency Market Research, 2018).

Data was randomly collected from the web-based survey and offline questionnaire in a comprehensive university in Changsha China from September 2017 to October 2017. After removing 26 invalid responses because of missing or completing the same answers, a total of 300 valid responses were collected for data analysis. Descriptive statistics are presented in Table 1.

Table 1. Demographic Profile of Participants $(N=300)$

\begin{tabular}{|c|c|c|c|}
\hline & Frequency & & Frequency \\
\hline Gender & & Education & \\
\hline Male & $106(35.3 \%)$ & High school \& diploma & $14(4.7 \%)$ \\
\hline Female & $194(64.7 \%)$ & Undergraduate student & $173(58 \%)$ \\
\hline Income (Yuan) & & Master's or doctorate & $113(37.3 \%)$ \\
\hline$<1500$ & $49(16.3 \%)$ & Age & \\
\hline $1500-3000$ & $32(10.7 \%)$ & $<24$ & $87(29.1 \%)$ \\
\hline $3001-5000$ & $71(23.7 \%)$ & $25-29$ & $127(42.3 \%)$ \\
\hline $5001-8000$ & $68(22.7 \%)$ & $30-34$ & $55(18.3 \%)$ \\
\hline$>8000$ & $80(26.6 \%)$ & $>35$ & $31(10.3 \%)$ \\
\hline
\end{tabular}

\section{Measures}

All measures are drawn from established works and adopt the backtranslation method to ensure questionnaire validity. Furthermore, two experienced marketing researchers were invited to adjust and modify the questionnaire in Chinese, according to some features of P2P website.

The questionnaire was divided into two parts. The first section includes six variables, i.e., photo-based social impression perception, host reputation, initial trust, consumer purchase probability, propensity to trust, and online accommodation booking experience. The second section of the survey included demographic questions.

The measured scale of social impression perception was generated from the combination of the research of White et al. (2017) and Bente et al. 
(2012), based on unique features of the short-term rental context, including two items such as perceived warmth and competence. The scale used to measure host reputation was adapted from Johnson and Grayson (2005), including two items. The three-item scale of initial trust was extracted from McKnight et al. (2002). Consumer purchase probability was measured with three items adopted from Parasuraman et al. (2005) and Nowlis and Simonson (1997). Propensity to trust is conceptualized as the general willingness to trust others (Cheung \& To, 2017), and three items were adapted from Zhao et al. (2015) and Gefen and Straub (2004). Lastly, online accommodation booking experience was measured with two items from $\mathrm{Wu}$ et al. (2017). All respondents were required to evaluate the degree of agreement or disagreement via a seven-point Likert scale $(1=$ strongly disagree, $7=$ strongly agree).

Additionally, six control variables, including propensity to trust, online accommodation booking experience, gender, age, education background, and income level were also measured, respectively.

\section{RESULTS}

\section{Manipulation Check}

To verify the manipulation of host reputation, manipulation and confound check were conducted. Independent sample t-tests showed that the ratings of host reputation were higher when the host had 5.0 stars than 3.0 stars $\left(\mathrm{M}_{\text {high }}=4.15, \mathrm{M}_{\text {low }}=3.56, t=3.06, p<0.05\right)$.

\section{Reliability and Validity}

SPSS 20.0 software was used to conduct the exploratory factor analysis and hypothesis testing. The KMO score of exploratory factor analysis (EFA) is 0.843, moreover, Bartlett's Sphere Test indicates that the sample is suitable for factor analysis.

To evaluate reliability, Cronbach's alpha coefficient value was used as an indicator. If the Cronbach's alpha coefficient of each variable exceeds the standard threshold value of 0.7 , data is considered reliable (Nunnally \& Bernstein, 1994). As shown in Table 2, all Cronbach's alpha coefficients were above 0.789 , fulfilling the data reliability requirements. 
Table 2. Measurement Statistics of Variables

\begin{tabular}{lcccc}
\hline Construct & $\begin{array}{c}\text { Indicator } \\
\text { Loadings }\end{array}$ & $\begin{array}{c}\text { Composite } \\
\text { Reliability }\end{array}$ & $\begin{array}{c}\text { Cronbach's } \\
\alpha\end{array}$ & $\begin{array}{c}\text { AVE } \\
\text { Value }\end{array}$ \\
\hline $\begin{array}{l}\text { Photo-based social impression } \\
\text { perception }\end{array}$ & & 0.730 & 0.835 & 0.575 \\
PSIP_1 & 0.744 & & & \\
PSIP_2 & 0.772 & & & \\
Host reputation & & 0.827 & 0.855 & 0.706 \\
HR_1 & 0.788 & & & \\
HR_2 & 0.889 & & & \\
Initial trust & & 0.896 & 0.920 & 0.742 \\
IT_1 & 0.828 & & & \\
IT_2 & 0.859 & & & \\
IT_3 & 0.896 & & & \\
Consumer purchase probability & & 0.755 & 0.714 & 0.513 \\
CPP_1 & 0.824 & & & \\
CPP_2 & 0.737 & & & \\
CPP_3 & 0.562 & & & \\
Propensity to trust & & 0.879 & 0.838 & 0.710 \\
PTR_1 & 0.721 & & & \\
PTR_2 & 0.888 & & & \\
PTR_3 & 0.906 & & & \\
Online accommodation booking & & 0.887 & 0.823 & \\
experience & & & & \\
OABE_1 & 0.890 & & & \\
OABE_2 & 0.895 & & & \\
\hline
\end{tabular}

To assess the construct validity, all variables' average variance extracted (AVE) is must be above 0.50 (Fornell \& Larcker, 1981). To establish convergent validity, each item loading needs to exceed the recommended threshold of 0.50 (Marriott \& Williams, 2018). Discriminant validity was considered next. The square root of variable's AVE value should be higher than correlations among itself and other variables. Table 2 and Table 3 show each variable was satisfying the established cut-off.

Table 3. Mean, Standard Deviation, Correlation and Square Root of AVE

\begin{tabular}{lrrrrrr}
\hline Variable & $\mathbf{1}$ & $\mathbf{2}$ & $\mathbf{3}$ & $\mathbf{4}$ & $\mathbf{5}$ & $\mathbf{6}$ \\
\hline 1 Social impression perception & $\mathbf{7 5 8}$ & & & & & \\
2 Host reputation & .601 & $\mathbf{. 8 4 0}$ & & & & \\
3 Initial trust & .656 & .496 & $\mathbf{. 8 6 1}$ & & & \\
4 Consumer purchase probability & .548 & .491 & .507 & $\mathbf{. 7 1 6}$ & & \\
5 Propensity to trust & .311 & .262 & .291 & .338 & $\mathbf{. 8 4 3}$ & \\
6 Online accommodation booking experience & .152 & .233 & .035 & .165 & .377 & $\mathbf{8 9 3}$ \\
Mean & 4.20 & 4.12 & 3.96 & 4.76 & 5.15 & 4.85 \\
Standard deviation & 1.40 & 1.18 & 1.25 & 1.11 & 1.46 & 1.11 \\
\hline
\end{tabular}


The potential common method deviation test was considered in three steps. At the beginning, the survey scope was expanded as much as possible, combining both online and offline questionnaire distribution, and the data source was controlled to a certain extent. Next, Harman's single factor test was conducted, and the results of exploratory factor analysis of all items showed that the first factor explained $36.83 \%$ of the total variance, which needed to be less than 50\% (Podsakoff et al., 2003). Lastly, considering the disadvantages of Harman's test, the double factor model was used to test again, that was, adding a first-order method factor with all of the measures as an indicator. If the method factor is added, the model fit will be highly optimized (i.e. CFI and TLI increase by more than 0.1 , RMSEA and SRMR decrease by more than 0.05), indicating there is a serious common method deviation (Wen et al., 2018). It was found that CFI and TLI increase by 0.038 and 0.053 separately, and RMSEA and SRMR decrease by 0.031 and 0.012 separately. In conclusion, the statement above underlines a lack of common method deviation in this research.

\section{Hypothesis Testing}

This study utilized multiple linear regression analysis to evaluate the conceptual framework, and the specific parameter estimates per model appear in Table 4. In each regression equation, variance inflation factor (VIF) values were in the range of 1.02 to 1.72 , which was below the threshold of 3.0; therefore, there was no serious multicollinearity problem (Hair et al., 2011).

Table 4. Results of Multiple Linear Regression Analysis

\begin{tabular}{|c|c|c|c|c|c|c|c|c|c|c|c|}
\hline & \multicolumn{6}{|c|}{ Consumer purchase probability } & \multicolumn{5}{|c|}{ Initial trust } \\
\hline & M1 & M2 & M3 & M4 & M5 & M6 & M7 & M8 & M9 & M10 & M11 \\
\hline Gender & .011 & -.011 & .039 & .027 & .007 & .039 & -.041 & -.069 & .001 & -.016 & -.025 \\
\hline Age & -.026 & -.044 & -.029 & -.039 & -.047 & -.035 & .035 & .012 & .030 & .022 & .010 \\
\hline Education & -.026 & -.005 & -.019 & .007 & -.010 & -.004 & -.084 & -.058 & -.074 & -.067 & -.063 \\
\hline $\begin{array}{l}\text { Income level } \\
\text { Online }\end{array}$ & .092 & .103 & .079 & .080 & .091 & .076 & .032 & .046 & .012 & .020 & .023 \\
\hline $\begin{array}{l}\text { accommodation } \\
\text { booking } \\
\text { experience }\end{array}$ & .039 & -.017 & .017 & .127 & .023 & -.040 & -.077 & $-.148^{*}$ & $-.110^{*}$ & $-.131^{*}$ & $-.130^{*}$ \\
\hline Propensity to trust & $.231^{*}$ & $.170^{*}$ & $.126^{*}$ & $.069^{*}$ & $.119^{*}$ & $.103^{*}$ & $.268^{*}$ & $.192^{*}$ & $0.111^{*}$ & $.109^{*}$ & $.101^{*}$ \\
\hline $\begin{array}{l}\text { Social impression } \\
\text { perception }\end{array}$ & & & $.421^{*}$ & & & $.292^{*}$ & & & $0.627^{* *}$ & $.526^{* *}$ & $0.538^{*}$ \\
\hline Host reputation & & $375^{*}$ & & & $.248^{*}$ & & & $.473^{*}$ & & $.173^{*}$ & $0.185^{*}$ \\
\hline Initial trust & & & & $.389^{*}$ & $.269^{*}$ & $.206^{*}$ & & & & & \\
\hline $\mathrm{SIP} \times \mathrm{HR}$ & & & & & & & & & & & $.092^{*}$ \\
\hline $\mathrm{R}^{2}$ & .126 & .300 & .340 & .309 & .368 & .371 & .107 & .311 & .457 & .476 & 0.484 \\
\hline$\triangle \mathrm{R}^{2}$ & .126 & .174 & .214 & .292 & .067 & .031 & .107 & .204 & .351 & .369 & 0.008 \\
\hline $\mathrm{F}$ & $7.063^{*}$ & $17.916^{*}$ & $21.495^{*}$ & $18.653^{*}$ & $21.157^{*}$ & $21.481^{*}$ & $5.833^{*}$ & $18.830^{*}$ & $35.163^{*}$ & $33.007^{*}$ & $30.251^{*}$ \\
\hline
\end{tabular}

Note: $\mathrm{N}=300$; Coefficients are standardized regression coefficients; ${ }^{* *} \mathrm{p}<0.01$. 
In Table 4, the effects of six control variables on consumer purchase probability were tested in M1. In M2 and M3, consumer purchase probability was considered as a dependent variable, and host reputation and social impression perception were considered as independent variables, separately. The results showed host reputation $(\beta=0.375, p<$ $0.01)$ and social impression perception $(\beta=0.421, p<0.01)$ had a positive effect on consumer purchase probability. Therefore, the results supported $\mathrm{H} 2$ and H4. In M4, using initial trust as an independent variable and consumer purchase probability as a dependent variable, it was found that initial trust $(\beta=0.389, p<0.01)$ significantly influenced consumer purchase probability. In M8 and M9, initial trust was considered as a dependent variable, and host reputation and social impression perception were considered as independent variables, separately. It was found that host reputation $(\beta=0.473, p<0.01)$ and social impression perception $(\beta=0.627$, $p<0.01)$ had a positive effect on initial trust. Hence, the results also supported H1 and H3. In M5 and M6, based on Wen and Ye (2014) and Baron and Kenny (1986) procedure, it was found that initial trust partially mediated the relationship between host reputation and consumer purchase probability, and social impression perception and consumer purchase probability separately, so H5a and $\mathrm{H} 5 \mathrm{~b}$ were also supported.

Given the potential questioning of the stepwise regression method to check mediation, the current research also adopted the non-parametric percentile method of bootstrap (5000) bias correction (BC) recommended by Hayes et al. (2008). The estimated specific indirect effect from social impression perception to consumer purchase probability through initial trust was 0.156 (95 per cent BC bootstrap $=0.0729,0.2427$ ), hence, H5a was supported. Likewise, $\mathrm{H} 5 \mathrm{~b}$ was also supported because the estimated specific indirect effect from host reputation to consumer purchase probability through initial trust was 0.139 (95 per cent BC bootstrap $=$ $0.0903,0.2010)$. These results suggested significantly partially mediated the impact of initial trust.

In Table 4, M7 was used to check the effects of six control variables on initial trust. In M10, host reputation and social impression perception were used as independent variables simultaneously and initial trust as dependent variable. To test the interaction effect between social impression perception and host reputation, negative and positive social impression groups were made by adding and subtracting the standard deviation, and then standardized all the variables in the regression equation in M11, and a new interaction term was created. Results of social impression perception $\times$ host reputation in Table 4 showed that the 
interaction had a significant effect on initial trust $(\beta=0.092, p<0.01)$. Comparing M11 with M10, the model fit significantly increased $\left(R^{2}=\right.$ $0.484, p<0.01$ ) after introducing interaction.

Findings showed that whenever in high or low reputation condition, positive photo-based social impression perceptions can lead to more significant initial trust (Figure 2). In addition, when considering the influence of positive social impression perception, high host reputation and interaction effect, initial trust is the most significant. Results suggested that positive photo-based social impression perception generates a complementary and strengthening effect on initial trust (Figure 2).

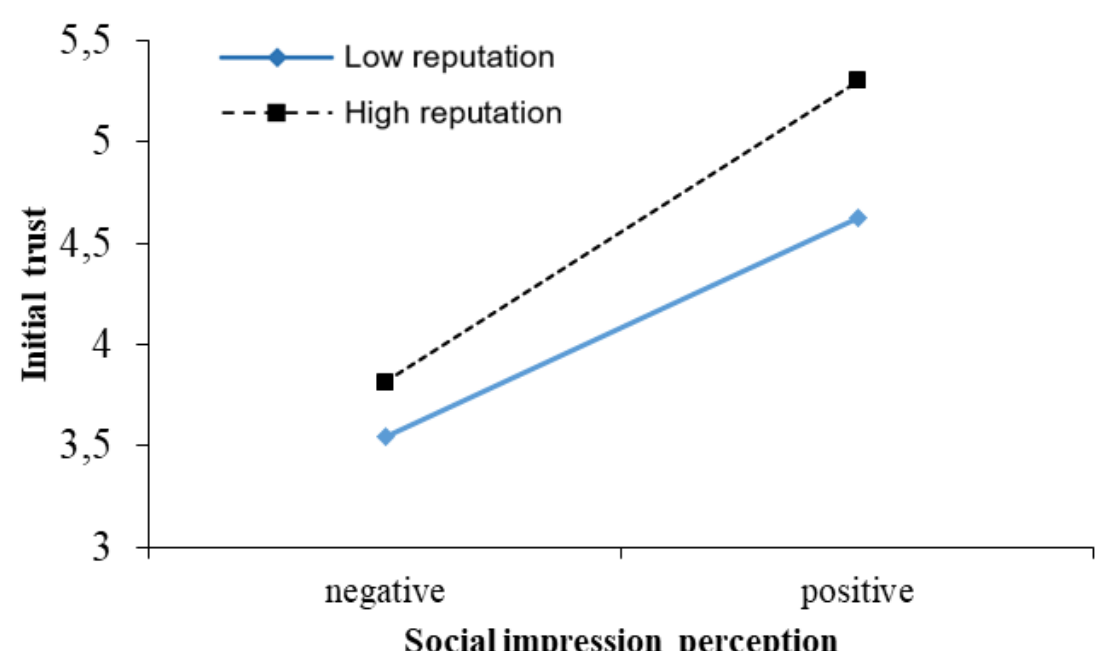

Figure 2. Interaction effect

\section{CONCLUSION AND IMPLICATIONS}

The study aimed at empirically investigating the impact of host photo and host reputation on consumer purchase probability. Following our arguments, photo-based social impression perceptions and reputation are positively related to initial trust and consumer purchase probability, which helps uncover the inherent mechanism. Simulated questionnaire method was utilized to analyze how the specific cues presented in the site interface (i.e. host's personal photo and reputation) are transformed into purchase probability. In particular, the findings highlight stronger evidence for host photo than host reputation to improve consumer 
purchase probability. According to Fagerstrøm et al. (2017), the influence of host photo ranked second to the room price.

Initial trust is a key performance mediator between independent variables (photo-based social impression perception and host reputation) and dependent variable (consumer purchase probability). As expected, after introducing the interaction item of host photo and reputation into the theoretical model, the model fit was improved significantly, indicating the existence of interaction effects. Authors infer the result is due to a different type of trust. There are two ways to trigger trust (Lewis \& Weigert, 1985). One way focuses on the integrated emotional bond between consumer and host, which results from sense and feeling rather than reasoning and understanding (emotional trust - host photo). Another way refers to consumers' rational judgement of the hosts' competence and relevant visual information (cognitional trust - host reputation). As a result, the combined effect of host photo and reputation on initial trust is greater than their separate individual utility.

\section{Theoretical and Practical Implications}

\section{Theoretical contributions}

Firstly, our study contributes to the Face Processing Theory by investigating photo-based social impression perceptions in the realm of P2P platform, therefore expanding the applied scope of this theory. Until now, studies on the impact of host photos in the P2P market have lagged far behind the practical development. Although several scholars have emphasized the multi-faceted perception of photographs in the field of interpersonal trust (Bente et al., 2012; Olivola et al., 2014), much remains unknown in the tourism P2P rental platform context. In the current study, perceived warmth and competence to measure photo-based social impression perception were taken, whereas the previous work documented how trustworthiness and attractiveness of photographs may shape consumers' purchase attitude and decision making (Ert et al., 2016; Yang, 2014). In doing this, the complementary examination of host photo sheds light on the blank of the multi-faceted perception in the P2P market and enriches the existing research framework to some extent.

Secondly, this paper initially explores the role of initial trust in the tourism field and enriches researches related to trust to a certain degree. Although there are research outcomes afterwards, figuring out the impact 
of initial trust in interpersonal relationship and online purchasing fields, only a few studies have paid attention to the online tourism field. Past research has addressed how initial trust can predict future purchase behavior (Lee et al., 2011; Lu et al., 2010); however, further relevant studies are urgently needed to clarify the antecedents of initial trust. In fact, the role of initial trust is revealed in this study as a mediator within the context of tourism short-term rental sites. In a word, this study contributes to the existing trust literature by confirming the importance of initial trust in the travel industry.

Thirdly, this research is the first to break down the previous independent factor research setting in the tourism field. Specifically, analysis of the joint influence of host photos and reputation on consumer trust behavior and purchasing intention was carried out. Results confirm that not only review ratings but also the host's personal information contribute to consumers' purchase decisions, which helps complete the stream of past studies and suggests a new path for better understanding consumers' psychological and behavioral decision making.

\section{Managerial implications}

According to research results, the following suggestions are put forward for P2P tourism platform managers and hosts.

Firstly, for hosts, the significant effect of hosts' individual photo on consumer purchase probability was found, which indicates that a positive or negative impression may be triggered by this type of content. Positive photos can lead to consumers' higher initial trust and purchase intention. More specifically, social impression perception was a more influential factor for consumer intention than reputation. Thus, the photo should be carefully selected, especially when the host has a low reputation. Nowadays, numerous hosts in the platform use anime and landscape pictures as avatars on the website. These types of pictures, being different from personal photos, cannot effectively convey sincere willingness to cooperate, but easily lead to negative impression for buyers, hindering further purchasing behaviors at the first stage of the transaction. Therefore, encouraging consumers to provide positive personal photos is a significant marketing strategy to convey cooperative and willful signals.

Secondly, our findings serve P2P online tourism operators. For instance, when hosts register, platform managers should inform them to 
upload appropriate personal photos. What is more, a host with a high review rating should be encouraged, whereas a host with a low rating should be supervised and urged to improve their services, to achieve winwin cooperation between platform companies and hosts.

Finally, this study's results can not only be applied to tourism short-term rental sites, but also to similar P2P online platforms with personal avatars, such as Mafengwo, Douban, and Tujia. These platforms might restrict users to use only personal photos to cultivate consumer trust. In the information era, due to information overload and asymmetry, searching costs seem high. Therefore, people can speed up their decisionmaking process by resorting to simple cues, for instance, host photos and reputation.

\section{Limitations and Future Research}

Like with other studies, there are certain limitations in the current research. First, this study narrowly focuses on the integrated perception of appearance cues inherent in photos. Other factors, such as shooting angle and gaze direction are also worth studying in future research. To keep the experimental stimulus as clean as possible, the main focus was on the overall photograph. However, further research could test whether findings of the current study could be replicated. Second, this research investigates external cues, i.e. host reputation and photo, yet many more cues influence consumers' behavior in real life. Hence, future research to approach this reality and explore whether there are other crucial factors should be encouraged. In addition, this research controls the interference of gender and age. It may be fruitful to examine the impacts of gender and age group on consumer attitude or behavior.

\section{REFERENCES}

Aimei, L., Wenquan, L., \& Lianyu, L. (2009). The implicit facial attractiveness stereotype research in personnel interview circumstances. Psychological Science, 32(4), 970973.

Baron, R. M., \& Kenny, D. A. (1986). The moderator-mediator variable distinction in social psychological research: Conceptual, strategic, and statistical considerations. Journal of Personality and Social Psychology, 51(6), 1173-1182.

Bente, G., Baptist, O., \& Leuschner, H. (2012). To buy or not to buy: Influence of host photos and reputation on buyer trust and purchase behavior. International Journal of Human-Computer Studies, 70(1), 1-13. 
Chang, Y., Xiao, W., Yan, J., Qiu, Y., \& Fu, J. (2014). Influence of service quality on phase trust under C2C environment. Chinese Journal of Management, 11(8), 1215-1223.

Cheung, M. F. Y., \& To, W. M. (2017). The Influence of the propensity to trust on mobile users' attitudes toward in-app advertisements: An extension of the theory of planned behavior. Computers in Human Behavior, 76, 102-111.

Doney, P. M., \& Cannon, J. P. (1997). An examination of the nature of trust in buyer-host relationships. Journal of Marketing, 61(2), 35-51.

Ennew, C., Kharouf, H., \&Sekhon, H. (2011). Trust in UK financial services: A longitudinal analysis. Journal of Financial Services Marketing, 16(1), 65-75.

Ert, E., Fleischer, A., \& Magen, N. (2016). Trust and reputation in the sharing economy: The role of personal photos in Airbnb. Tourism Management, 55, 62-73.

Fagerstrøm, A., Pawar, S., Sigurdsson, V., Foxall, G. R., \& Yani-de-Soriano, M. (2017). That personal profile image might jeopardize your rental opportunity! On the relative impact of the host's facial expressions upon buying behavior on Airbnb. Computers in Human Behavior, 72, 123-131.

Fornell, C., \& Larcker, D. F. (1981). Evaluating structural equation models with unobservable variables and measurement error. Journal of Marketing Research, 18, 39-50.

Gefen, D., \& Straub, D. W. (2004). Consumer trust in B2C e-commerce and the importance of social presence: Experiments in e-products and e-services. Omega, 32(6), 407424.

Hayes, A. F., Slater, M. D., \& Snyder, L. B. (2008). The sage sourcebook of advanced data analysis methods for communication research. London, UK: Sage.

Hair, J. F., Ringle, C. M., \& Sarstedt, M. (2011). PLS-SEM: Indeed a silver bullet. Journal of Marketing Theory and Practice, 19(2), 139-51.

Hayne, S. C., Wang, H., \& Wang, L. (2015). Modeling reputation as a time-series: Evaluating the risk of purchase decisions on eBay. Decision Sciences, 46(6), 10771107.

Hui, X., Saeedi, M., Shen, Z., \& Sundaresan, N. (2016). Reputation and regulations: Evidence from eBay. Management Science, 62, 3604-3616.

Jarvenpaa, S. L., Tractinsky, N., \& Saarinen, L. (2000). Consumer trust in an internet store: A cross-cultural validation. Journal of Computer-Mediated Communication, 1(1-2), 45-71.

Johnson, D., \& Grayson, K. (2005). Cognitive and affective trust in service relationships. Journal of Business Research, 58(4), 500-507.

Joo, J. (2015). Roles of the buyer's trust in host in posted-price model of consumer to consumer e-commerce. Journal of Theoretical \& Applied Electronic Commerce Research, 10(3), 30-44.

Kucukusta, D., Law, R., Besbes, A., \& Legohérel, P. (2015). Re-examining perceived usefulness and ease of use in online booking: The case of Hong Kong online users. International Journal of Contemporary Hospitality Management, 27(2), 185-198.

Lee, J. N., \& Choi, B. (2011). Effects of initial and ongoing trust in IT outsourcing: A bilateral perspective. Information and Management, 48(2), 96-105.

Lewis, J. D., \& Weigert, A. (1985). Trust as a social reality. Social Forces, 63(4), 967-985.

Lu, Y., Zhao, L., \& Wang, B. (2010). From virtual community members to C2C ecommerce buyers: Trust in virtual communities and its effect on consumers' purchase intention. Electronic Commerce Research \& Applications, 9(4), 346-360.

Ma, X., Hancock, J. T., Mingjie, K. L., \& Naaman, M. (2017). Self-disclosure and perceived trustworthiness of Airbnb host profile. Proceedings of the 2017 ACM Conference on 
Computer Supported Cooperative Work and Social Computing. Portland, Oregon, USA, February 25 - March 01, 2017.

Marriott, H. R., \& Williams, M. D. (2018). Exploring consumers perceived risk and trust for mobile shopping: A theoretical framework and empirical study. Journal of Retailing \& Consumer Services, 42(1), 133-146.

McKnight, D. H., Choudhury, V., \& Kacmar, C. (2002). The impact of initial consumer trust on intentions to transact with a website: A trust building model. Journal of Strategic Information Systems, 11(3), 297-323.

Melnik, M. I., \& Alm, J. (2005). Host reputation, information signals, and prices for heterogeneous coins on eBay. Southern Economic Journal, 72, 305-328.

National Information Center (2018). China shared accommodation development report 2018. Retrieved December 18, 2018, from www.sic.gov.cn/index.htm

Nowlis, S. M., \& Simonson, I. (1997). Attribute-task compatibility as a determinant of consumer preference reversals. Journal of Marketing Research, 34(2), 205-218.

Nunnally, J. C., \& Bernstein, I. H. (1994). Psychometric theory (3 ${ }^{\text {rd }}$ ed.). New York, NY: McGraw-Hill

Olivola, C. Y., \& Todorov, A. (2010). Elected in 100 milliseconds: Appearance-based trait inferences and voting. Journal of Nonverbal Behavior, 34(2), 83-110.

Olivola, C. Y., Eubanks, D. L., \& Lovelace, J. B. (2014). The many (distinctive) faces of leadership: Inferring leadership domain from facial appearance. Leadership Quarterly, 25(5), 817-834.

Parasuraman, A., Zeithaml, V. A., \& Malhotra, A. (2005). E-S-Qual: A multiple-item scale for assessing electronic service quality. Journal of Service Research, 7(3), 213-233.

Podsakoff, P. M., MacKenzie. S. B., Lee. J. Y., \& Podsakoff, N. P. (2003). Common method biases in behavioral research: A critical review of the literature and recommended remedies. Journal of Applied Psychology, 88(5), 879-903.

Ridings, C. M., Gefen, D., \& Arinze, B. (2002). Some antecedents and effects of trust in virtual communities. Journal of Strategic Information Systems, 11(3-4), 271-295.

Smith, J. (2018). From broke to billionaires: The rise of Airbnb founders who rented out air mattresses in their apartment for $\$ 80$-a-night to make rent and now run a \$30billion global travel empire. Retrieved December 18, 2018, from https://www.dailymail.co.uk/news/article-5918039/From-broke-billionaires-riseAirbnb-founders.html

Stirrat, M., \& Perrett, D. I. (2010). Valid facial cues to cooperation and trust: Male facial width and trustworthiness. Psychological Science, 21(23), 349-354.

Stouthuysen, K., Teunis, I., Reusen, E., \& Slabbinck, H. (2018). Initial trust and intentions to buy: The effect of vendor-specific guarantees, customer reviews and the role of online shopping experience. Electronic Commerce Research \& Applications, 27, 2338.

Todorov, A., Mandisodza, A. N., Goren, A., \& Hall, C. C. (2005). Inferences of competence from faces predict election outcomes. Science, 308(5728), 1623-1626.

Todorov, A., Olivola, C. Y., Dotsch, R., \& Mende-Siedlecki, P. (2015). Social attributions from faces: Determinants, consequences, accuracy, and functional significance. Annual Review of Psychology, 66(1), 519-45.

Todorov, A., Pakrashi, M., Oosterhof, N. N. (2009). Evaluating faces on trustworthiness after minimal time exposure. Social Cognition, 27(6):813-833.

Transparency Market Research. (2018). Peer-to-peer Lending market to be worth US $\$ 897.85$ billion by 2024 - TMR. Retrieved December 29, 2018, from 
https://www.prnewswire.com/news-releases/peer-to-peer-lending-market-to-beworth-us-897-85-billion-by-2024-tmr-883066968.html

Wang, Z., Mao, H., Li, Y. J., \& Liu, F. (2016). Smile big or not? Effects of smile intensity on perceptions of warmth and competence. Journal of Consumer Research, 43(5), 787805.

Wen, Z., Huang B., \& Tang D. (2018). Preliminary work for modeling questionnaire data. Journal of Psychological Science, 41(1), 204-210.

Wen, Z., \& Ye, B. (2014). Analyses of mediating effects: The development of methods and models. Advances in Psychological Science, 22(5), 731-745.

White, D., Sutherland, C. A. M., \& Burton, A. L. (2017). Choosing face: The curse of self in profile image selection. Cognitive Research Principles \& Implications, 2(1), 1-9.

Willis, J., \& Todorov, A. (2010). Making up your mind after a $100 \mathrm{~ms}$ exposure to a face. Psychological Science, 17(7), 592-598.

$\mathrm{Wu}, \mathrm{W}$. Y., Huang, P. C., \& Fu, C. S. (2011). The influence of an online auction's product price and e-retailer reputation on consumers' perception, attitude, and behavioral intention. Scandinavian Journal of Psychology, 52, 290-302.

Wu, W. Y., Quyen, P. T. P., \& Rivas, A. A. A. (2017). How e-servicescapes affect customer online shopping intention: The moderating effects of gender and online purchasing experience. Information Systems and e-Business Management, 15, 689715.

Xie, K., \& Mao, Z. (2017). The impacts of quality and quantity attributes of Airbnb hosts on listing performance. International Journal of Contemporary Hospitality Management, 29(3), 2240-2260.

Xu, F., Cai, W., Ma, F., \& Wu D. (2013). Evaluation of face trustworthiness and its relationship with trust propensity. Studies of Psychology and Behavior, 1(4), 433-439.

Yang, X. (2014). The role of photographs in online peer-to-peer lending behavior. Social Behavior \& Personality, 42(3), 445-452.

Zhao, H., Wang, X., \& Zhou, B. (2015). Relationship among interaction, presence and consumer trust in B2C online shopping. Management Review, 27(2), 43-54. 